\title{
KINERJA PENYULUH PERTANIAN PADA SEKOLAH LAPANG PENGELOLAAN TANAMAN TERPADU DI KECAMATAN PANOMBEIAN PANEI KABUPATEN SIMALUNGUN
}

\author{
THE PERFORMANCE OF AGRICULTURAL EXTENSION IN THE FIELD OF THE \\ SCHOOL INTEGRATED CROP MANAGEMENT IN PANOMBEIAN PANEI \\ DISTRICT, SIMALUNGUN REGENCY
}

\author{
YUDI CHAHYANTO SIMANJUNTAK, FUAD HASAN \\ Program Studi Agribisnis, Fakultas Pertanian, Universitas Trunojoyo Madura \\ Email: yudi.simanjuntak92@gmail.com
}

\begin{abstract}
ABSTRAK
Penyuluh pertanian merupakan salah satu bagian dari petugas lapang yang menjadi ujung tombak keberhasilah pada Sekolah Lapang Pengelolaan Tanaman Terpadu (SL-PTT). Oleh karenanya keberhasilan pelaksanaan SL PTT di lapangan terletak pada kinerja penyuluh pertanian dan petugas lapang lainnya. Tujuan dari penelitian ini adalah (1) mengetahui kinerja penyuluh pertanian pada SLPTT menurut persepsi petani, dan (2) mengetahui hubungan karakteristik petani dengan persepsi petani terhadap kinerja penyuluh pertanian pada SL-PTT. Sampel petani sejumlah 40 petani diambil dengan teknik multi-stage random sampling. Data kumpulkan dengan teknik wawancara berdasarkan daftar pertanyaan yang sudah disusun sebelumnya. Data dianalisis menggunakan analis deskriptif dan analisis chi-square. Hasil penelitian menunjukkan bahwa kinerja penyuluh pertanian menurut persepsi petani sudah berkategori baik. Karakteristik petani yang berhubungan nyata pada persepsi petani terhadap kinerja penyuluh pertanian adalah tingkat pendidikan formal, luas lahan, dan intensitas kehadiran petani dalam kegiatan penyuluhan.
\end{abstract}

Kata Kunci : persepsi, kinerja, penyuluh pertanian

\begin{abstract}
The agriculture extention is one of the field officers who spearhead the success of the Integrated Crop Management Field School (SL-PTT). Therefore the successful implementation of SL-PTT in the field lies in the performance of agricultural extension workers and other field officers. The purpose of this study is (1) to find out the performance of agricultural instructors in SL-PTT according to farmers' perceptions, and (2) to know the relationship between farmers' characteristics and farmers' perceptions of the performance of agricultural extension workers in SL-PTT. A sample of 40 farmers was taken using a multi-stage random sampling technique. Data collected by interview technique based on a list of questions that have been prepared previously. Data were analyzed using descriptive analysis and chi-square analysis. The results showed that the performance of agricultural instructors according to farmers' perceptions was categorized as good. Farmer characteristics that are significantly related to farmers 'perceptions of the performance of agricultural instructors are the level of formal education, land area, and the intensity of farmers' presence in extension activities.
\end{abstract}

Keywords: perception, performance, agricultural extension 


\section{PENDAHULUAN}

Konsumsi beras per kapita penduduk indonesia cenderung mengalami penurunan dimana pada tahun 1981 sebesar 116,75 kg/kapita/tahun turun menjadi $84,90 \mathrm{~kg} / \mathrm{kapita} /$ tahun pada tahun 2015 (Kementerian Pertanian, 2016). Namun demikian, seiring dengan jumlah penduduk pertahun yang semakin meningkat maka kebutuhan terhadap beras diprediksikan juga semakin meningkat (Yanuarti \& Afsari, 2016). Dalam upaya pemenuhan tersebut, pemerintah telah menetapkan kebijakan ketahanan pangan, yang salah satunya adalah swasembada beras (selain jagung dan kedelai) yang berkelanjutan (Ernawati et al, 2015).

Salah satu bentuk startegi pemerintah dalam upaya mencapai swasembada beras yang berkelanjutan yaitu dengan melakukan Sekolah Lapang Pengelolaan Tanaman Terpadu (SL-PTT) sejak tahun 2008 (Rusastra, Supriadi, \& Ashari, 2013) dengan mendesiminasikan penerapan inovasi dan teknologi budidaya padi secara langsung kepada petani (Heriawan et al., 2016). Sejalan dengan tujuan program swasembada berkelanjutan, SL-PTT bukan hanya sekedar untuk meningkatkan produktivitas padi tetapi juga untuk meningkatkan pendapatan petani dan kelestarian lingkungan (Deptan, 2008).

SL-PTT merupakan bentuk proses belajar-mengajarnya dilakukan di lapangan. Sebagaimana proses belajar mengajar pada umumnya, dibutuhkan adanya guru atau dalam SL-PTT disebut sebagai Pemandu Lapang (PL). Pemandu lapang dalam SL-PTT terdiri dari penyuluh pertanian pengamat organisme pengganggu tanaman, dan pengawas benih tanaman (Deptan, 2008). Kinerja pemandu lapang merupakan ujung tombak keberhasilan pelaksanaan SL-PTT di lapangan. Oleh karena itu, pemandu lapang dituntut mempunyai kinerja yang baik untuk mendukung tercapainya tujuan SLPTT.

Salah satu wilayah yang menjadi lokasi diterapkannya SL-PTT padi selama ini yaitu Kecamatan Panombeian Panei Kabupaten Simalungun. Tetapi produktivitas padi di Kecamatan Panombeian Panei (57,62 kg/hektar) masih lebih kecil dibandingkan beberapa kecamatan lainnya, seperti di Kecamatan Tanah jawa yang mencapai 63,49 kg/hektar (BPS, 2019). Hal tersebut menunjukaan bahwa tujuan SL-PTT belum tercapai dengan maksimal. Tentunya banyak faktor yang dapat mempengaruhi terhadap keberhasilan tercapainya tujuan 
SL-PTT, diantaranya adalah kinerja petugas penyuluh yang berperan sebagai pemandu lapang.

Penelitian ini berfokus pada faktor petugas penyuluh karena jika dilihat dari perbandingan antara jumlah penyuluh dengan jumlah gabungan kelompok tani di Kecamatan Panombeian Panei tidak ideal. Menurut Lampiran Peraturan Menteri Pertanian Nomor: 72/Permentan/Ot.140/10/2011 Tanggal 31 Oktober 2011 tentang Pedoman Formasi Jabatan Fungsional Penyuluh Pertanian menyatakan bahwa penempatan penyuluh Pertanian di desa/kelurahan ditetapkan sebagai berikut: a) apabila dalam satu desa terdapat lebih besar atau sama dengan delapan poktan, maka ditempatkan 1 (satu) orang penyuluh; b) apabila dalam satu desa terdapat kurang dari delapan poktan, maka ditempatkan satu penyuluh untuk membina dua desa. Sedangkan menurut catatan BPS (2019), petugas penyuluh di Kecamatan Panombeian Panei berjumlah 11 orang dengan jumlah kelompok tani sebanyak 147 dan gapoktan sebanyak 7 gapoktan yang tersebar di 11 nagori atau desa.

Menurut Mathis et al.(2016), kinerja pegawai dapat dinilai oleh atasan, sesama pegawai, pihak luar, dan juga pegawai itu sendiri (menilai dirinya sendiri). Penyuluh pertanian yang merupakan pegawai pemerintah di Badan Penyuluh Pertanian juga demikian. Petani sebagai mitra kerja penyuluh pertanian dapat dianggap sebagai pihak luar yang mengetahui kinerja penyuluh selama berintraksi sehingga petani dapat menjadi pihak yang dapat dimintai penilaian terhadap kinerja penyuluh. Penilaian petani terhadap kinerja penyuluh tidak dapat lepas dari unsur subjektifitas yang dipengaruhi oleh karakteristik yang melekat pada individu petani (Ardiansyah, et al., 2014; Sari et al., 2015; Zulfikar et al., 2018).

Berdasarkan pada uraian di atas, penelitian ini bertujuan untuk mengetahui kinerja penyuluh dari persepsi petani dan untuk mengetahui karakteristik petani dengan persepsi petani terhadap kinerja penyuluh SL-PTT di Kecamatan Panombeian Panei Kabupaten Simalungun

\section{METODE PENELITIAN}

Penelitian ini dilakukan pada periode Maret - April 2019. Populasi penelitian adalah anggota kelompok tani di Kecamatan Panombeian Panei yang mengikuti SP-PTT. Adapun kelompok tani yang menjadi peserta SL-PTT 14 kelompok. Sampel sebanyak 40 orang petani diambil dengan teknik multi-stage random sampling. Langkah pertama adalah 
menentukan 4 sampel kelompok tani yang tersebar di Desa Simpang Panei, Desa Pematang Pane, Desa Panombean, dan Desa Pamatang Panombean. Langkah kedua menentukan sampel petani pada masing-masing kelompok 10 petani sehingga.

Data primer dikumpulkan dengan teknik wawancara menggunakan panduan kuisioner yang sudah diuji validitas dan reliabilitasnya. Kuisioner untuk mengukur kinerja disusun dengan 20 pertanyaan yang dibuat dengan mengacu pada indikator kinerja dari Mathis \& Jackson (2012) yaitu: jumlah pekerjaan yang diselesaikan, kualitas pekerjaan yang diselesaikan, kerjasama, kehadiran, dan lamanya penyelesaian pekerjaan. Adapun skala pengukuran untuk setiap pertanyaan adalah skala likert 1-4.

Analisis dilakukan dengan dua pendekatan yaitu deskriptif dan inferensia. Analisis deskriptif dilakukan untuk mengukur kinerja dengan cara menghitung nilai rerata skor untuk kemudian dibuat kategori (tidak baik, cukup baik, baik). Adapun interval skor dan kategorinya ditunjukkan pada tabel 1 berikut:

Tabel 1. Batasan Interval Skor dan Kategorinya

\begin{tabular}{cc}
\hline Interval skor & Kategori \\
\hline $1,0-2,0$ & Tidak baik \\
$2,1-3,0$ & Cukup Baik \\
$3,1-4,0$ & Baik \\
\hline
\end{tabular}

Analisis inferensial menggunakan Chi Square digunakan untuk menjawab rumusan masalah yang kedua. Kriteria pengambilan keputusannya adalah Apabila nilai Chi Square hitung > nilai Chi Square tabel $(\alpha=0,05)$ maka menerima $\mathrm{H}_{1}$ dan menolak $\mathrm{H}_{0}$, begitu juga sebaliknya apabila nilai Chi Square hitung < nilai Chi Square tabel $(\alpha=0,05)$ maka menerima $\mathrm{H}_{0}$ dan menolak $\mathrm{H}_{1}$. Adapun hipotesis dalam penelitian ini adalah sebagai berikut.

$\mathrm{H}_{0}=$ Faktor umur, tingkat pendidikan formal, lama berusahatani, luas lahan, status kepemilikan lahan, dan intensitas interaksi petani dengan penyuluh pertanian tidak berhubungan dengan persepsi petani terhadap kinerja penyuluh pertanian.

$\mathrm{H}_{1}=$ Faktor umur, tingkat pendidika formal, lama berusahatani, luas lahan, status kepemilikan lahan, dan intensitas interaksi kelompok tani dengan penyuluh pertanian berhubungan dengan persepsi petani terhadap kinerja penyuluh pertanian.

\section{HASIL DAN PEMBAHASAN}




\section{Karaktersitik Responden Berdasarkan}

\section{Variabel Pelitian}

Penelitian ini menggunakan 40 petani dengan karakteristik yang diduga menjadi faktor mempengaruhi persepsi petani terhadap kinerja penyuluh pertanian adalah umur, tingkat pendidika formal, lama berusahatani, luas lahan, status kepemilikan lahan, dan intensitas kehadiran petani dalam penyuluhan. Distribusi karakteristik responden ditunjukkan pada tabel 2 .

bisanya berbading lurus dengan tingkat pengetahuan dan keterbukaan terhadap inovasi

dan teknologi baru sehingga dimungkinan akan mempunyai cara berusahatani yang lebih baik.

Tabel 2. Karakteristik Responden $(n=40)$

\begin{tabular}{|c|c|c|}
\hline Karakteristik & Jumlah & Persentase \\
\hline 1. Umur (tahun) & & \\
\hline $36-46$ & 20 & $50,0 \%$ \\
\hline $47-56$ & 17 & $42,5 \%$ \\
\hline $57-65$ & 3 & $7,7 \%$ \\
\hline Tingkat pendidikan & & \\
\hline $\mathrm{SD}$ & 2 & $5,0 \%$ \\
\hline SLTP & 8 & $20,0 \%$ \\
\hline SLTA & 30 & $75,0 \%$ \\
\hline Lama berusahatani (tahun) & & \\
\hline $5-15$ & 15 & $37,5 \%$ \\
\hline $16-25$ & 17 & $42,5 \%$ \\
\hline $26-36$ & 8 & $20,0 \%$ \\
\hline Luas lahan (hektar) & & \\
\hline $0,2-0,8$ & 23 & $57,5 \%$ \\
\hline $0,81-1,40$ & 13 & $32,5 \%$ \\
\hline $1,41-2,0$ & 4 & $10,0 \%$ \\
\hline 5. Status lahan & & \\
\hline Milik sendiri & 13 & $32,5 \%$ \\
\hline Sewa & 27 & $67,5 \%$ \\
\hline $\begin{array}{l}\text { 6. Intensitas kehadiran petani dalam } \\
\text { penyuluh (kali/musim tanam) } \\
4\end{array}$ & & \\
\hline 5 & 13 & $32,5 \%$ \\
\hline 6 & 11 & $27,5 \%$ \\
\hline & 16 & $40,0 \%$ \\
\hline
\end{tabular}

Sumber: data primer, 2019

Berdasarkan pada pengalaman berusahatani, responden sudah
Tabel 2 menunjukkan, sebagian besar responden berada pada usia produktif (dibawah 64 tahun) dimana usia termuda adalah 36 tahun dan tertua 65 tahun. Jika dilihat dari distibusinya, responden berusia diantara 36 - 46 tahun adalah paling banyak (50\%). Berdasarkan pada pendidikannya, sebagian besar responden mempunyai pendidikan formal yang bukan pendidikan dasar yaitu $75 \%$ berpendidikan SLTA. Tingkat pendidikan

ditunjukkan pada tabel 2. aik. 
berusahatani padi selama 16 - 25 tahun. Dalam pengololaan Usahatani, semakin lama petani berusahatani maka petani semakin terbiasa, semakin mahir dan semakin terampil dalam melakukan kegiatan usahatani sehingga berdampak pada semakin tingginya produksi usahatani yang dapat dihasilkan (Mulyati, 2014). Berdasarkan pada luas lahan sawah garapannya, responden menggarap sawah seluas 0,2 hektar sampai 2 hektar. Sebagian besar $(57,5 \%)$ menggarap 0,2 0,8 hektar.

Berdasarkan pada status lahannya, sebagian besar responden (67,5\%) menggarap sawah dengan sistem sewa. Status kepilikan lahan dapat berpengaruh terhadap efisiensi dan produktivitas usahatani. Petani dengan lahan sewa mempunyai tingkat efisiensi usahatani lebih tinggi dibandingkan milik sendiri (Hasan et al., 2016). Demikian juga dengan produktivitas, lahan sewa mempunyai produktivitas lebih tinggi dibandingkang tidak sewa (Rondhi \& Adi, 2018).

Peertemuan antara penyuluh dengan petani biasa dilaksanakan rutin baik di kantor BPP maupun di Desa.
Selama satu musim tanam padi, pertemuan yang riil dilaksanakan sebanyak 6 kali. Sebagian besar petani (60\%) tidak dapat menghadiri semua pertemuan yang dijadwalkan dengan berbagai alasan.

\section{Kinerja Penyuluh Pertanian Menurut Persepsi Petani}

Menurut Mathis et al.(2016), salah satu pihak yang dapat menilai kerja seseorang adalah pihak luar. Petani merupakan pihak diluar lembaga penuluhan. Kinerja penyuluh pertanian sebagai pemandu lapang pada SL PTT di Panombeian Panei Kabupaten Simalungun menurut penilaian petani sudah baik dengan skor 3,25 (skala 1-4), tetapi masih dapat ditingkatkan skornya karena baru mencapai $81,25 \% \quad\left(=\frac{\mathbf{3 , 2 5}}{\mathbf{4}} \boldsymbol{x} \mathbf{1 0 0} \%\right)$ dari skor maksimal. Persepsi petani terhadap kinerja penyuluh pertanan merupakan penilaian atau tanggapan petani terhadap hasil kerja penyuluh pertanian. Penilaian petani terhadap kinerja penyuluh pertanian secara keseluruhan dapat dilihat pada tabel 3.

Tabel 3

Persepsi Petani terhadap Kinerja Penyuluh Pertanian

\begin{tabular}{ccc}
\hline Indikator & Nilai & Keterangan \\
\hline Quantity of work (kuantitas kerja) & 3,21 & Baik
\end{tabular}




\begin{tabular}{ccc} 
Quality of work (kualitas kerja) & 3,14 & Baik \\
Compability with others (kerja sama) & 3,37 & Baik \\
Presence of work (kehadiran kerja) & 3,40 & Baik \\
Length of service (lama layanan) & 3,15 & Baik \\
\hline Total & $\mathbf{3 , 2 5}$ & Baik \\
\hline
\end{tabular}

\section{Sumber: Data Primer Diolah, 2019}

Tabel 3 menunjukkan bahwa penilaian petani terhadap lima indikator kinerja penyuluh pertanian berada pada kategori baik, tapi skor untuk semua indikator belum maksimal yang artinya masing-masing indikator kinerja penyuluh masih dapat diusahakan untuk lebih tinggi. Terdapat tiga indikator yang mempunyai skor di bawah skor kinerjanya yaitu kuantitas kerja, lamanya pelayanan, dan kualitas kerja. Indikator kuantitas kerja mempunyai skor paling rendah $(3,14)$ diantara indikator lainnya. Rendahnya indikator tersebut karena menurut petani, penyuluh tidak melaksanakan semua pertemuan yang sudah direncanakan diawal kegiatan sekolah lapang. Pada tahap perencanaan kegiatan yang disusun bersama antara petugas lapang yang didalamnya terdapat petugas penyuluh, telah dibuat jadwal pertemuan rutin antara penyuluh dengan petani minimal 8 kali pertemuan selama sekali musim tanam. Adapun tempat pertemuan ditentukan di Balai Penyuluh Pertanian dan di Desa dilaksanakannya SL-PTT.

Indikator yang mempunyai skor terendah kedua adalah lamanya layanan
$(3,15)$. Meskipun skornya sudah berkategori baik, tetapi masih ada petani yang merasa bahwa durasi waktu yang disediakan penyuluh dalam pertemuan baik untuk penyuluhan maupun konsultasi masih dirasa kurang sehingga apa yang disampaikan penyuluh tidak bisa komprehensif dan konsultasi tidak bisa tuntas.

Indikator lain yang mempunyai skor di bawah skor kinerja adalah indikator kualitas kerja $(3,21)$. Pada indikator ini, petani mempunyai penilaian paling rendah (diantara 12 pertanyaan lainnya) pada pertanyaan "penyuluh mampu memberikan solusi terhadap masalah yang dihadapi petani" dan "penyuluh mudah ditemui/dihubungi untuk berkonsultasi”. Menurut para petani, solusi yang diberikan penyuluh pertanian belum mampu mengatasi masalah yang dihadapi petani sampai dengan tuntas. Sedangkan yang terkait dengan kemudahan petani menghubungi penyuluh untuk berkonsultasi, menurut sebagian petani, ketika petani hendak bertemu penyuluh di luar jadwal pertemuan sering ditanggapi oleh penyuluh pertanian. Hal ini 
dikarekanakan adanya kesibukan penyuluh pertanian ketika petani tersebut hendak melakukan konsultasi langsung di luar waktu pertemuan rutin. Tetapi pada dasarnya penyuluh siap membantu petani setiap saat. Hal ini dirasakan sebagian petani yang sudah memanfaatkan teknologi (misal, aplikasi Whats App) untuk berkonsultasi dengan penyuluh tanpa bertemu langsung sehingga penyuluh dapat menjawab kapanpun.

\section{Hubungan Karakteristik Petani dengan \\ Persepsi Petani terhadap Kinerja Penyuluh Pertanian}

Penelitian ini menduga bahwa karakteristik petani yang berhubungan dengan persepsi petani dalam menilai kinerja penyuluh pertanian adlaah umur petani, tingkat pendidikan formal, lama berusahatani, luas lahan, status kepemilikan lahan, dan intensitas interaksi petani dengan penyuluh pertanian. Faktorfaktor yang berhubungan dengan persepsi petani terhadap kinerja penyuluh pertanian akan disajikan pada tabel 4.

Tabel 4

Faktor yang Berhubungan dengan Persepsi Petani terhadap Kinerja Penyuluh Pertanian

\begin{tabular}{lcc}
\hline \multicolumn{1}{c}{ Faktor } & $\begin{array}{c}\text { Chi Square } \\
\text { Hitung }\end{array}$ & $\begin{array}{c}\text { Chi Square } \\
\text { Tabel }\end{array}$ \\
\hline Umur petani & 48,410 & 49,244 \\
Tingkat pendidikan formal & 50,611 & 49,244 \\
Lama berusahatani & 39,114 & 49,244 \\
Luas lahan & 51,538 & 49,244 \\
Status kepemilikan lahan & 14,017 & 26,498 \\
Intensitas kehadiran petani dalam penyuluhan & 60,923 & 49,244 \\
\hline
\end{tabular}

Sumber: Data Primer Diolah, 2019

Umur Petani. Nilai Chi Square hitung untuk variabel umur diketahui sebesar 48.410 sedangkan nilai Chi Square tabelnya dengan hasil penelitian yang dilakukan adalah sebesar 49.244. Dengan demikian, oleh Zulfikar et al. (2018) yang dapat diketahui bahwa nilai Chi Square hitung (48.410) < Chi Square tabel (49.244), sehingga menerima $\mathrm{H}_{0}$ menolak $\mathrm{H}_{1}$ yaitu faktor umur tidak berhubungan dengan penilaian persepsi petani terhadap kinerja penyuluh pertanian. Hal ini sejalan menyatakan bahwa umur petani tidak memberikan pengaruh terhadap pembentukan persepsi petani terhadap kompetensi penyuluh pertanian tanaman pangan baik itu petani muda, dewasa maupun tua. Hasil penelitian yang sama 
juga dilakukan oleh Sari et al.(2015) bahwa umur petani tidak berhubungan nyata dengan tingkat persepsi petani terhadap kinerja penyuluh dalam pengembangan padi organic di Kecamatan Pagelaran Kabupaten Pringsewu. Umur tidak memiliki kontribusi secara langsung terhadap persepsi petani terhadap kinerja penyuluh.

\section{Tingkat pendidkan formal. Nilai}

Chi Square hitung untuk variabel tingkat pendidikan formal sebesar 50.611 dan nilai Chi Square tabel ( $\mathrm{df}=40, \mathrm{a}=15 \%)$ adalah sebesar 49.244. Hasil ini menunjukkan bahwa nilai Chi Square hitung > nilai Chi Square tabel sehingga menerima $\mathrm{H}_{1}$ dan menolak $\mathrm{H}_{0}$ yaitu faktor tingkat pendidikan formal berhubungan dengan persepsi petani terhadap kinerja penyuluh pertanian di Kecamatan Panombeian Panei Kabupaten Simalungun. Artinya adalah semakin tinggi tingkat pendidikan petani, maka semakin tinggi atau semakin baik pula persepsinya terhadap kinerja penyuluh pertanian. Temuan hasil penelitian ini mendukung hasil penelitian Sari et al.(2015) dan Ardiansyah et al.( 2014) yang menyatakan bahwa lama pendidikan petani berhubungan nyata dengan tingkat persepsi petani terhadap kinerja penyuluh pertanian, dimana semakin tinggi tingkat pendidikan petani akan meningkatkan persepsinya terhadap kinerja penyuluh pertanian, tetapi berbeda dengan hasil penelitian Zulfikar et al.(2018) yang menyatakan bahwa tingkat pendidikan formal petani tidak berhubungan nyata dengan persepsi petani terhadap kompetensi penyuluh.

Lama berusahatani. Nilai $C h i$ Square hitung untuk variabel lama berusahatani sebesar 39.114 dan nilai $C h i$ Square tabel $(\mathrm{df}=40$ dan $\mathrm{a}=15 \%)$ adalah sebesar 49.244. Hal ini berarti bahwa nilai Chi Square hitung < nilai Chi Square tabel yang artinya menerima $\mathrm{H}_{0}$ dan menolak $\mathrm{H}_{1}$ yaitu faktor lama berusahatani tidak berhubungan dengan persepsi petani terhadap kinerja penyuluh pertanian. Semakin lama atau banyak pengalaman berusahatani responden tidak berpengaruh dengan persepsinya terhadap kinerja penyuluh pertanian karena responden akan menilai kinerja peyuluh atas manfaat yang diterima petani dan hubungan sosial yang terjalin. Hal ini sejalan dengan penelitian yang dilakukan oleh Ardiansyah et al.(2014) bahwa lama berusahatani tidak berhubungan dengan persepsi petani terhadap kinerja penyuluh pertanian di Kecamatan Metro Barat Kota Metro. Hasil penelitian yang sama juga dikemukakan oleh Sari et al. (2015) bahwa pengalaman berusahatani tidak memiliki kontribusi 
terhadap kinerja penyuluh di Kecamatan Pagelaran Kabupaten Pringsewu.

Luas lahan. Nilai Chi Square hitung variabel luas lahan sebesar 51.538 dan nilai Chi Square tabel $(\mathrm{df}=40$ dan $\mathrm{a}=$ $15 \%$ ) adalah sebesar 49.244. Hal ini menunjukkan bahwa nilai Chi Square hitung < nilai Chi Square tabel sehingga menerima $\mathrm{H}_{1}$ dan menolak $\mathrm{H}_{0}$ yaitu variabel luas lahan berhubungan dengan persepsi petani terhadap kinerja penyuluh pertanian. Sejalan dengan apa yang dikemukakan oleh Narti (2015) bahwa semakin sempit lahan akan mempengaruhi tingkat kerumitan yang akan dihadapi, sehingga bagi petani yang hanya memiliki luas lahan sedikit cenderung kurang tertarik dan kurang merasa cocok untuk menerapkan program SL-PTT. Hal ini berbeda dengan hasil penelitian yang dilakukan oleh Zulfikar et al.(2018) bahwa tidak terdapat hubungan nyata antara luas lahan petani dengan persepsi petani terhadap kompetensi penyuluh pertanian tanaman pangan di Kabupaten Aceh Utara. Artinya seberapapun luas lahan yang dimiliki oleh kelompok tani tidak akan mempengaruhi persepsinya terhadap kinerja penyuluh pertanian.

Status kepemilikan lahan. Nilai Chi Square hitung sebesar 14.017 dan nilai Chi Square tabel $(\mathrm{df}=20$ dan a $=15 \%)$ adalah sebesar 26.498. Hal ini menunjukkan bahwa nilai Chi Square hitung < nilai Chi Square tabel yang berarti bahwa menerima $\mathrm{H}_{0}$ dan menolak $\mathrm{H}_{1}$ yaitu faktor status kepemilikan lahan tidak berhubungan dengan persepsi petani terhadap kinerja penyuluh pertanian. Hal ini sejalan dengan hasil penelitian yang dilakukan oleh (Farida, 2012) bahwa tidak terdapat hubungan yang nyata antar status kepemilikan lahan dengan persepsi responden terhadap kompetensi PPL di Kecamatan Pontang, Kabupaten Serang. Namun berbeda dengan hasil penelitian yang dilakukan oleh Zulfikar et al.(2018) bahwa terdapat hubungan nyata antara status kepemilikan lahan dengan persepsi petani terhadap kompetensi penyuluhan pertanian tanaman pangan dalam penerapan metode yang dilaksanakan oleh penyuluh. Artinya semakin tinggi kepemilikan lahan milik sendiri petani maka akan semakin tinggi persepsinya terhadap penerapan metode yang dilakukan oleh penyuluh dalam kegiatan penyuluhan.

\section{Intensitas kehadiran petani dala} kegiatan penyuluh. Nilai Chi Square hitung pada variabel intensitas interaksi petani dengan penyuluh adalah 60.923 dan nilai Chi Square tabel $(\mathrm{df}=40$ dan $\mathrm{a}=15)$ adalah sebesar 49.244. Hal ini berarti bahwa nilai Chi Square hitung > nilai Chi 
Square tabel sehingga menerima $\mathrm{H}_{1}$ dan menolak $\mathrm{H}_{0}$ yaitu faktor intensitas interaksi petani dengan penyuluh pertanian berhubungan dengan persepsi petani terhadap kinerja penyuluh pertanian. Hal ini sejalan dengan hasil penelitian yang dilakukan oleh Ardiansyah et al.(2014) dan Sari et al.(2015) bahwa interaksi sosial (baik interaksi petani dengan penyuluh, sesama anggota kelompok tani, sesama petani) memiliki kontribusi secara langsung terhadap persepsi petani terhadap kinerja penyuluh. Maknanya adalah semakin sering petani berinteraksi dengan penyuluh maka akan semakin tinggi persepsi petani terhadap kinerja penyuluh.

\section{KESIMPULAN DAN SARAN}

Kenerja penyuluh pertanian pada SL-PTT Kecamatan Panombeian Panei dianggap baik oleh petani. Karakteristik petani yang berhubungan dengan persepsi petani terhadap kinerja penyuluh pertanian adalah tingkat pendidikan formal, luas lahan, dan intensitas interaksi kelompok tani dengan penyuluh pertanian. Sedangkan faktor yang tidak berhubungan dengan persepsi petani terhadap kinerja penyuluh pertanian adalah faktor umur, lama berusahatani dan status kepemilikan lahan.
Kinerja penyuluh pertanian pada SL-PTT di Kecamatan Panombeian Panei berkategori baik, keberhasilan SL-PTT belum maksimal yang ditunjukkna oleh produktivitas padai di Kecamatan Panombeian Panei masih lebih rendah dibandingkan Kecamatan yang ada di Kabupaten Simalungun. Hal ini dapat diduga bahwa kurang berhasilnya SL-PTT di Kecamatan Panombeian Panei bukan karena kinerja punyuluh, tetapi dipengaruhi faktor lainnya seperti kinerja penyulih lapang lain (selain penyuluh lapang), implementasi SL-PTT oleh petani dan itu perlu dilakukan penelitian lebih lanjut.

\section{DAFTAR PUSTAKA}

Ardiansyah, A., Sumaryo, G., \& Yanfika, H. (2014). Persepri Petani terhadap Kinerja Penyuluh Pertanian Sebagai Model COE (Center of Excelence) Kecamatan Metro barat Kota Metro. JIIA, 2(2), 182-189.

BPS. (2019). Kabupaten Simalungun Dalam Angka 2019-1.pdf. Simalungun: BPS.

Deptan. (2008). Panduan Pelaksanaan Sekolah Lapang Pengelolaan Tanaman Terpadu (SL-PTT) Jagung. Jakarta: Departemen Pertanian.

Ernawati, Djafar, L., \& Sudirman. (2015). PROGRAM SEKOLAH LAPANGAN PENGELOLAAN TANAMAN KAPASITAS PETANI. Jurnal Tesis PMIS- 
UNTAN, 1-21.

Farida, I. (2012). Persepsi Petani terhadap Kompetensi Penyuluh Pertanian Lapangan di Kecamatan Pontang, Kabupaten Serang, Provinsi Banten. Disertasi.

Hasan, F., Darwanto, D. H., \& Adiyoga, W. (2016). The Impact of Cropping Pattern and Land Tenure Status to Technical Efficiency of Shallots Farming in Nganjuk Regency , Indonesia. 7(16), 128-133.

Heriawan, R., Suryana, A., Saliem, P., Ariani, M., Kariyasa, I. K., \& Yofa, R. D. (2016). Kebijakan Swasembada Pangan Berkelanjutan: Komponen Strategis Dalam Perspektif Masyarakat Ekonomi Asean 2015 (I. W. Rusastra \& S. H. Susilowati, Eds.). Jakarta: Kementerian Pertanian Republik Indonesia.

Kementerian Pertanian. (2016). Outlook Komoditas Pertanian Sub Sektor Tanaman Pangan: Padi. Jaka: Kementerian Pertanian Republik Indonesia.

Mathis, R. ., \& Jackson, J. H. (2012). Human Resource Management (13th ed.). Mason, USA: SouthWestern Cengange Learning.

Mathis, R. L., Jackson, J. H., \& Valentine, S. R. (2016). Human Resource Management (14th ed.). Mason, USA: Cengange Learning.

Mulyati, H. (2014). Analisis Produksi dan Pendapatan Usahatani Padi Sawah di Desa Jono Oge Kecamatan Sigi Biromaru Kabupaten Sigi. E-J. Agrotekbis, 2(1), 54-61.
Narti, S. (2015). Hubungan Karakteristik Petani dengan Efektivitas Komunikasi Penyuluhan Pertanian dalam Program SL-PTT (Kasus Kelompok Tani di Kecamatan Kerkap Kabupaten Bengkulu Utara. Jurnal Profesional FIS UNIVED, 2(2).

Rondhi, M., \& Adi, A. H. (2018). Pengaruh Pola Pemilikan Lahan Terhadap Produksi, Alokasi Tenaga Kerja, dan Efisiensi Usahatani Padi. AGRARIS: Journal of Agribusiness and Rural Development Research, 4(2), 101-110.

Rusastra, I. W., Supriadi, H., \& Ashari. (2013). Kinerja Program SL-PTT Padi Nasional: Analisis Persepsi dan Reorientasi Kebijakan Pengembangan Kedepan. Analisis Kebijakan Pertanian, 11(2), 129147.

Sari, J., Nurmayasari, I., \& Yanvika, H. (2015). Persepsi Petani terhadap Kinerja Penyuluh dalam Pengembangan Padi Organik di Kecamatan Pagelaran Kabupaten Pringsewu. JIIA, 3(4), 432-439.

Yanuarti, A. R., \& Afsari, M. D. (2016). Profil Komoditas Barang Kebutuhan Pokok dan Barang Penting Komoditas Beras. Jakarta: Kementerian Perdagangan RI.

Zulfikar, Amanah, S., \& Asngari, P. S. (2018). Persepsi Petani terhadap Kompetensi Penyuluh Pertanian Tanaman Pangan di Kabupaten Aceh Utara. Jurnal Penyuluhan, 14(1), 159-174. 